\title{
Sociedad de riesgo y necesidad de una fundamentación del Derecho en la persona humana considerada metafísicamente
}

\author{
Risk Society and the Need a Metaphysical \\ Foundation of the Law: An Analysis Based \\ on the Thinking of Dworkin and Kaufmann
}

\author{
Édgar Antonio Guarín Ramírez *
}

Fecha de recepción: 14 de abril de 2008 Fecha de aprobación: 21 de abril de 2008

\section{Resumen}

En el pensamiento de algunos de los grandes filósofos del Derecho de las últimas décadas, como R. Dworkin y A. Kaufmann, se encuentra una constante insistencia en la necesidad de tomarse los derechos de las personas en serio -palabras de Dworkin-, y de establecer un Derecho de contenido material que sea análogo a la persona humana -en palabras de Kaufmann. Esta necesidad se hace aún más imperiosa en la actualidad, si se tiene en cuenta que se vive en una sociedad de riesgo mundial que, a través de la investigación científica efectuada sobre el ser humano, ha puesto al ser humano frente a un sinnúmero de cuestiones, que exigen no perder de vista algunos criterios claros de orden antropológico que, a su vez, se constituyan en máximas de verdad "no negociables", so pena de poner en riesgo la permanencia del hombre sobre la tierra.

Esos criterios deben ser la base del derecho y constituir su razón de ser. Esta afirmación lleva a plantear, desde la perspectiva del realismo filosófico aristotélico-tomista -el cual irriga cada vez con más amplitud

Filósofo y abogado, Especialista en Ciencias Religiosas. Docente de la Universidad Santo Tomás. Candidato a Magíster en Derecho Público. Docente e investigador de varias universidades, miembro del grupo Raimundo de Peñafort reconocido por Colciencias en categoría A, autor de varios artículos sobre Filosofía y teoría del Derecho, y co-autor del texto: Filosofía y teoría del derecho: Tomás de Aquino en diálogo con Kelsen, Hart, Dworkin y Kaufmann. Universidad Santo Tomás 2006 
el pensamiento actual como se demuestra a lo largo de este artículo-, la necesidad de fundamentar el derecho en la persona, pero respetando la radicalidad de su ser, lo que implica que deba ser concebida metafísicamente. Dicha concepción metafísica, indica lo que es la realidad del "de suyo" humano -para ponerlo en términos del gran filósofo español X. Zubiri-; realidad que se impone como el límite que no puede ser rebasado por la ciencia, so pena, de poner en riesgo la propia preservación de la especie humana en el mundo.

\section{Palabras clave}

Realismo filosófico, idealismo filosófico, sociedad de riesgo mundial, bioética, derechos en serio, derecho análogo a la persona, metafísica, naturaleza humana.

\section{Abstract}

In the thinking of some of the most significant legal philosophers of the last decades, such as R. Dworkin and A. Kaufmann, one can find the permanent insistence on the need for taking the personal rights seriously, as well as establishing a law which is not only implemented but also takes into account the economic and social necessities of the people. Nowadays, this need is even more pertinent, given the fact that we live in a society of worldwide risks, in which mankind has to face - among other things due scientific research on the human being - a number of serious challenges. One of them is that we must acknowledge those anthropological criterions which constitute non-negotiable, absolute truths.

These criterions must be the basis of the law as well as its reason to be. This claim leads us to state - from the perspective of the Aristotelian-Thomistic philosophical realism, which influences with more and more impetus the current thinking - the necessity of founding the law based on the human being itself, while respecting the radicality of its existence. This concept implicates that the human being must be understood metaphysically. Also, it points out the reality of the human de suyo - to use a term by the Spanish philosopher $X$. Zubiri -, a reality which represents a limit that may not be exceeded by science so as not to put in danger the very existence of mankind.

\section{Key words}

Philosophic realism, philosophic idealism, society of worldwide risk, bioethics, worldwide risk society, metaphysics, human nature

\section{INTRODUCCIÓN}

Con el idealismo moderno también llegó el antropocentrismo y la primacía del sujeto a la filosofía; con ellos, la sustitución de la noción de ente (ens-entis) -concepto fundamental de la filosofía clásica-, por la de objeto (objectum). En la filosofía antigua y me- dieval había conciencia clara de que el ente existía con independencia del sujeto que lo conocía. Sin embargo, con la Modernidad, el objeto sólo es objeto para el sujeto que lo aprehende, y como tal, no existe independientemente de él. La consecuencia de esto: la reducción de la realidad, a la noción de "objeto", y la correspondiente negación de lo metafísico. 
Desde mi perspectiva, esta seguidilla de proposiciones constituyen la explicación del hecho de que una de las ideas más recurrentes en algunos de los principales filósofos del Derecho de los últimos cincuenta años, como R. Dworkin y A. Kaufmann, sea la negativa de aceptar que la fundamentación de sus teorías tenga algo que ver con la metafísica. La pretensión propia del positivismo científico de alcanzar conocimientos "puros" en las diferentes áreas del saber, entre ellas el Derecho, se relaciona mucho con esta negativa. No obstante, en ellos también se ha podido evidenciar un fuerte llamado de atención con respecto a la necesidad de no reducir el Derecho a una mera dogmática, sobre todo, en los tiempos actuales que por lo convulsionados han hecho que se califique a nuestra sociedad como "de riesgo". Por ello, la relación entre Derecho y axiología se erige hoy en día, nuevamente, como uno de los temas de mayor importancia y relevancia para la Filosofía del Derecho.

En las siguientes páginas, el lector encontrará algunos argumentos que me han llevado a plantear la tesis de que en la actualidad es urgente y necesario, frente a la actual sociedad de riesgo mundial, recuperar la fundamentación del derecho en la persona humana, pero concebida metafísicamente, la cual se ha perdido con el advenimiento del idealismo moderno. Esta tesis surge como consecuencia del análisis de algunos aspectos del pensamiento de dos de los principales filósofos del Derecho contemporáneo: Ronald Dworkin y Arthur Kaufmann, que no son de tendencia realista, sino idealista, y cuya influencia en iusfilosofía actual es innegable.

No obstante, Dworkin y Kaufmann rechazan -de manera más o menos explícita- la idea de fundamentar metafísicamente el Derecho, por ello terminan aludiendo a su necesidad -también de manera más o menos explícita- y lo terminan haciendo, en razón de su compromiso con la necesidad de dar respuesta a las problemáticas más urgentes que le plantea la sociedad actual al Derecho. Así lo hizo
Tomás de Aquino, el gran maestro medieval del siglo XIII; por su parte, estos iusfilósofos leen las necesidades de su tiempo, coinciden en que en las actuales circunstancias se necesita un derecho con "contenido material", para lo cual acuden al concepto de persona o de dignidad de la persona humana, el cual exige, a su vez, un referente a la antropología filosófica y, a través de ella, a la metafísica, que permite penetrar en lo que es propio del hombre, en su esencia, en su "de suyo" -como lo llama el gran filósofo español X. Zubiri-, a fin de poder determinar objetivamente el contenido de esa excelencia o especial dignidad que posee la realidad personal del ser humano.

\section{RONALD DWORKIN Y LA NECESIDAD DE TOMARSE LOS DERECHOS DE LAS PERSONAS "EN SERIO"}

Ronald Dworkin, iusfilósofo norteamericano nacido en 1931, es considerado uno de los mayores pensadores anglosajones contemporáneos en los campos de la filosofía jurídica y política; en su compilación de ensayos, Los derechos en serio -escrita en la década del setenta-, da una importancia fundamental a la moral y a la política en el Derecho, al punto que plantea lo que denomina "naturalismo jurídico". Según Dworkin, ese "naturalismo" no coincide con la idea del derecho natural, toda vez que no cree en la existencia de un derecho anterior al derecho positivo que le sirva de fundamento; ese derecho está constituido por principios unitarios, universales e inmutables, que Dworkin se niega a aceptar. Con esto, se ve un rechazo abierto al "modelo de razonamiento" iusnaturalista, que, para él, parte de la idea de la existencia de una moral objetiva que el hombre pueda y deba descubrir.

Frente a este rechazo del modelo de razonamiento, usado por el iusnaturalismo, Dworkin propone reemplazarlo por el modelo de razonamiento rawlsiano. Ese modelo está fundamentado en 
la hipótesis de una "posición original" en la que puestos los seres racionales pueden establecer los principios de justicia y de Derecho que van a regir a una sociedad. Se quiere llamar la atención en que, a pesar de que Dworkin ataca el modelo de razonamiento iusnaturalista y de que acepta el contractualista desarrollado por J. Rawls, Dworkin es enfático en afirmar que no se puede atentar contra la dignidad de la persona, bajo ninguna circunstancia; eso incluye el acuerdo o pacto sobre los referidos principios del derecho y la justicia. De lo anterior se infiere que el contenido de lo que Dworkin llama "dignidad humana" no puede estar sujeto a regateos o acuerdos; por ende, tiene un significado objetivo que supera la mera suma de subjetividades. De no ser así, cualquier cosa se podría defender como acorde con esa dignidad -incluso los mismos atentados contra la vida humana-, con lo cual, según Dworkin, no se estaría tomando "en serio" los derechos de las personas. Pues bien, ese "objetivo" no es otra cosa que el ser mismo del hombre, por lo tanto, es un concepto antropológico y metafísico a la vez.

Dworkin se plantea la siguiente pregunta en el texto de los Derechos en serio: ipor qué los derechos en serio? A la cual responde:

Cualquiera que declare que se toma "los Derechos en serio", y que elogie a nuestro gobierno por respetarlos, debe tener alguna idea de qué es ese algo. Debe aceptar, como mínimo, una o dos ideas importantes. La primera es la idea, vaga pero poderosa, de la dignidad humana [...] La segunda es la idea, más familiar, de la igualdad política, que supone que los miembros más débiles de una comunidad política tienen derecho, por parte del gobierno, a la misma consideración y el mismo respeto que se han asegurado para sí los miembros más poderosos, de manera que si algunos hombres tienen libertad de decisión, sea cual fuere el efecto de la misma sobre el bien general, entonces todos los hombres deben tener la misma libertad (Dworkin, 1997, p. 44).
En la cita anterior hay una alusión directa a la dignidad humana. Aunque la califique de "idea vaga pero poderosa", se podría llegar a afirmar que Dworkin, por el estrecho vínculo que establece entre la moral, la política y el derecho, jamás estaría de acuerdo con la violación de esa dignidad de la persona. Tan es así que cuando se refiere al concepto del derecho como "integridad" quiere significar que la realidad jurídica es creada como expresión de una correcta concepción de la justicia y de la equidad y además es creada sobre la base de esa dignidad humana, por la cual los jueces están en capacidad de identificar los derechos y los deberes legales de las personas. Esa "integridad" del derecho es la que permite al juez hallar, de entre un grupo de principios coherentes sobre los derechos y deberes de la persona, la mejor interpretación posible que integre la estructura política, la moral política y la doctrina legal de la comunidad.

Concebir el derecho como integridad supone para Dworkin una estructura que pone por encima de todo lo demás, incluso sobre el derecho positivo en vigor, algunos valores básicos que se desprenden de tal noción de integridad; valores como la justicia, la imparcialidad y la equidad; valores fundamentados en la "dignidad humana". En últimas, se trata de una subordinación de la norma de derecho a los principios morales y políticos de la comunidad que conforman, como un todo estrechamente unido, la integridad del Derecho, en la cual sólo los jueces de la integración -los "Hércules" de su teoría- pueden encontrar la interpretación correcta, sobre la base del imperativo que plantea: "tomarse los derechos de las personas en serio".

Es por ello que el propio Dworkin asevera que "cuando la promulgación de una ley afecta los derechos que efectivamente se tienen, el ciudadano puede seguir su propio juicio [...] ya que la ley puede ser tan injusta que la obligación de obedecerla, deja de existir" (Dworkin, 1997, p. 54). 
Esto significa que con anterioridad al derecho positivo habría una especie de norma jurídica natural -estas palabra no son de Dworkin sino mías-, cuyo fundamento radicaría en la dignidad de la persona humana -esta idea sí es de Dworkin.

\section{ARTHUR KAUFMANN Y LA NECESIDAD DE UN DERECHO DE CONTENIDO MATERIAL QUE SEA ANÁlOGO A LA PERSONA}

Arthur Kaufmann, iusfilósofo alemán, discípulo de Gustav Radbruch, tiene una concepción del Derecho, que rotula con el nombre de "concepción analógica" y que acerca mucho a la fundamentación metafísica del derecho. Según esta concepción de la realidad jurídica, en el Derecho se da una correspondencia entre ser y deber ser (Kaufmann, 1999, pp. 130 y 267). Por eso, tanto en la creación del derecho como en su aplicación, a través de un procedimiento analógico, Kaufmann junta la realidad con la norma; esa unión tiene lugar en la ratio iuris o sentido. En esa realidad, a partir de la que surge la norma y que es necesaria para su aplicación, está la persona humana, que emerge como el fundamento, tanto para la creación como para la aplicación del derecho.

Dentro de esta dinámica de raciocinio, Kaufmann plantea que en el proceso de creación y de aplicación del derecho existe una construcción escalonada; en consecuencia, distingue tres escalones: el primero lo conforman los principios jurídicos abstractos, a los que llama "idea de derecho", que son generales, suprapositivos y suprahistóricos; el segundo lo conforman la reglas o normas positivas; el tercero lo conforma el derecho concreto, material, positivo e histórico, esto es, la decisión jurídica. Esta construcción escalonada, lleva a Kaufmann aseverar, en primer lugar, que no es posible obtener el derecho sin criterio valorativo -en contra del positivismo- $y$, en segundo lugar, que toda corriente normativa unilateral se debe rechazar, ya que ellas sólo miran el criterio valo- rativo y creen posible que a partir de allí se puede llegar, sin más ni más, al derecho real. Es por eso que llama a su teoría "una tercera vía" entre el iusnaturalismo y el iuspositivismo.

Es necesario resaltar la atención sobre la manera en que -según Kaufmann- se construyen los principios que integran el primer escalón. Para él, dichos principios, si bien emergen del curso de la historia, se inscriben y fundamentan en la misma realidad del ser humano, al que define como "relación". Al describir esos principios pone como ejemplos: el honeste vivere, el suum cuique tribuere, el neminem laedere, el imperativo categórico kantiano, el de equidad de Rawls y el principio de la tolerancia, que es formulado por el propio Kaufmann. Una vez descritos estos principios, afirma que en todos ellos hay un elemento común: la persona aparece como su núcleo y criterio fundamental. Así pues, es a partir de la realidad de la persona humana, que surgen los principios del derecho que, al momento de ser aplicados, tienen que abrirse al espacio fáctico vital, es decir, materializarse; se trata del ser y del deber ser que se entrelazan.

La unificación del derecho y de la ley que se dio en la Modernidad es la causa, según Kaufmann, de que la validez del Derecho se hubiera derivado y limitado al poder del soberano. En esto radicó la ruptura de los rasgos materiales y formales de la ley; un acontecimiento que para él fue profundamente nefasto en la evolución histórica del Derecho, porque el contenido de la ley comenzó a no importar; lo que importaba era la voluntad del soberano. En ese contexto, el juez era simplemente un autómata, "un computador" (Kaufmann, 1999, p. 277), un mero realizador de inferencias lógicas, de raciocinios deductivos desarrollados por medio del modelo paradigmático del silogismo deductivo, ya en forma de de silogismos categóricos (modus barbara-celarent-darii-ferio), hipotéticos (modus ponente ponens o tollendo 
tollens), o disyuntivos (modus ponendo tollens o tollendo ponens) ${ }^{1}$.

Lo anterior condujo a que en la Modernidad surgieran leyes oprobiosas para la humanidad. Sin duda, Kaufmann está pensando en la Alemania Nazi, sobre la que su maestro G. Radbruch escribiera en su ensayo "Relativismo y derecho". Según Kaufmann, solamente si se tiene en cuenta el contenido de la ley, que tiene que ser análogo a la persona, es posible catalogar una ley como injusta, como "no derecho".

Toda la concepción analógica descrita lleva a A. Kaufmann a afirmar que se necesita un concepto real de derecho, que indique algo sobre su contenido y sobre su realidad, más allá de la mera realidad de la ley (Kaufmann, 1999, pp. 279-280). El camino que propone para llegar a ese concepto real de derecho es el referente a las condiciones de vida concretas de las personas. A partir de la norma sólo puede resultar derecho concreto, a través del contacto con las condiciones de vida reales. Así pues, el derecho real surge al poner en concordancia la realidad y la norma que necesita correspondencia recíproca (Kaufmann, 1999, p. 283); pero esa correspondencia tiene como fundamento último la realidad de la persona humana.

1 La concepción analógica del Derecho planteada por Kaufmann, se extiende también hasta su aplicación. Para explicar esa "aplicación analógica", plantea la denominada "teoría de la equiparación". Según esta teoría, puesto que propiamente ni la ley general-abstracta, ni el caso individual-concreto se encuentran en el mismo plano categorial, pues la ley está en el plano del deber ser y el caso en el plano del ser, para que pueda operar la subsunción del caso bajo la ley, primero tiene que darse la equiparación: de la ley, por medio de la interpretación, a la consecuencia jurídica; y del caso, por medio de la construcción, al supuesto de hecho. Estos actos se dan en una simultaneidad de relaciones recíprocas. De esta manera, no se trata de una mera subsunción del caso bajo la norma, sino del supuesto de hecho bajo la consecuencia jurídica. Es un ejercicio hermenéutico. Después de establecer la equiparación, ley y caso dejan de ser lo que eran y eso es lo que constituye el núcleo de la historicidad del Derecho. Allí aparece, nuevamente, la analogía entre ser y deber ser. La norma abstracta del deber ser alcanza en el derecho -en el ser- su concreta existencialidad.
El hecho de afirmar que la validez del derecho no pasa solamente por lo formal, sino que también requiere un contenido material que sea análogo a la persona, lleva a Kaufmann a plantear que frente a las leyes antijurídicas, que se caracterizan por la irracionalidad y la injusticia, que atentan contra la misma persona humana, contra sus derechos que son componente fundamental de cualquier sistema jurídico y que son propias de un Estado que no es de derecho, es posible ejercer derecho a la resistencia, esto es, la posibilidad de desobedecer la ley positiva, cuando ella es injusta. Frente a tales normas, no es posible aplicar el principio de tolerancia, porque los Derechos Humanos fundamentales tienen un núcleo sustancial que no puede ser relativizado: la persona, ser en relación con el otro, que tiene sus propios derechos, pero que tiene que convivir con los derechos de los otros.

La centralidad que Kaufmann le da a la persona, en su Filosofía del Derecho, es innegable. Tan es así, que llama a la persona: "categoría fundamental sobre la que se construye y aplica el derecho"; ella es el "analogante" del Derecho; es el concepto clave a la hora de entender correctamente lo que es la justicia social y los Derechos Humanos. Tan importante es la persona en Kaufmann que incluso Ilega a afirmar que ella es el objeto de la ciencia del Derecho, con lo cual se acerca mucho a su concepción realista, en la cual su objeto material es la persona, su conducta, su ser relacional, y el objeto formal es la justicia.

Pero hace falta abordar otra cuestión, antes de cerrar este análisis, y que, apenas se ha tocado someramente: es la noción de persona que maneja Kaufmann. A lo largo de estas líneas se ha referido en varias ocasiones que Kaufmann define la persona como "ser de relación". Para explicar esta noción dice que su concepto de persona es ontológico- procesal; ahora bien, por "ontológico" se entiende "relacional", por lo tanto, el hombre es un ser de relación con las cosas y con los otros. 
Por otra parte, "procesal" indica que la persona es el punto partida a la hora de construir el derecho; expresamente dice que esta visión ontológicoprocesal es una alternativa frente a la que denomina "concepción ontológico-substancial del ser humano", que se niega a aceptar.

No obstante, es interesante ver cómo, al final de su libro Filosofía del derecho, que esta concepción ontológico-substancial del hombre cuando habla de su abierta oposición a las técnicas de clonación humana dice que ellas son "incompatibles con la dignidad humana que se apoya en la individualidad no intercambiable y en la unicidad de la persona" (Kaufmann, 1999, p. 556) Sin duda alguna, los términos empleados por Kaufmann en esta frase son metafísicos, se quiera o no aceptarlo, y las dos características en las cuales se asienta la dignidad de la persona humana (individualidad y unicidad) son dos categorías que no son producto de la vida de relación de las personas, sino que hacen parte de esa realidad individual, ontológicosustancial, que pretendía negar.

\section{LA FUNDAMENTACIÓN DEL DERECHO EN LA PERSONA DESDE EL REALISMO FILOSÓFICO}

Los análisis precedentes sobre el pensamiento de estos dos iusfilósofos llevan a la convicción de que es imposible fundamentar el derecho en la persona, haciendo caso omiso de su realidad metafísica. Tanto Dworkin como Kaufmann tácitamente aluden esa realidad, la cual, desde mi perspectiva, tiene que ser el sustentáculo de la reflexión iusfilosófica actual, toda vez que constituye, sin lugar a dudas, un faro desde el cual se puede iluminar con espléndida luz la situación de riesgo que actualmente se vive en el mundo, y a la cual el Derecho no puede ser ajeno.

Aunque se pretenda negar la fundamentación metafísica del Derecho, que deviene a través de una concepción metafísica de la persona -quizá debido también a una mala intelección de lo que es la metafísica-, la realidad del Derecho y de la persona, como su fundamento, muestran que ella es no sólo posible, sino también actual y necesaria. Al respecto, tengo el firme convencimiento de que el metafísico y el científico -en este caso los científicos del Derecho- tienen muchos elementos en común, porque ambos comparten el impulso básico del entendimiento hacia la verdad, tal como se ha venido demostrando a través de estas líneas. Por su parte, el realismo escoge un camino -acertado y seguro para mí-, que es distinto al camino del idealismo; es el camino que se atiene a la cosa misma, a la realidad misma, no vista como objectum, sino como ens, lo cual no es otra cosa que la vía metafísica. Por ese camino, se analiza la estructura categorial de la realidad jurídica y, a través de su estudio, se plantean principios, que son fundamentales para su intelección y de los cuales no se puede hacer caso omiso. Esa vía de estudio de la realidad jurídica, que conduce a la realidad personal del ser humano, la cual, abordada también metafísicamente, muestra unos radicales de su ser que no pueden ser quebrantados. De la existencia de esos radicales, dan buena cuenta las filosofías de Dworkin y Kaufmann, aunque el sistema de pensamiento que es base de su pensamiento no es el realismo, sino el idealismo.

La penetración en la realidad del Derecho, en su última esencia, muestra que éste no es la norma positiva, como bien lo afirma Kaufmann. La norma apenas es un título de derechos; pero ese título también puede estar en la realidad del ser humano, en su naturaleza ${ }^{2}$. Estos derechos o bienes, que pertenecen a la persona por ser integrantes de sus

2 Tan real es esto que, incluso, el más positivista de los positivistas no se refiere al derecho de una persona en términos de norma. Por eso, no dice: "el derecho de $A$, es el artículo ' $x^{\prime \prime}$; sino que dice: usted tiene derecho a la educación, o a la vida o a la salud. 
ser -sobre los que la persona tiene el más riguroso y estricto dominio- engendran en los demás el deber de respeto y, en caso de daño o lesión injustos, el deber de restitución y, de no ser posible, el de compensación, como bien lo afirma el iusfilósofo español Javier Hervada (2000, pp. 167-169).

Sólo si se comprende que existen tales derechos naturales, que preexisten a la decisión de la sociedad y a la ley positiva, se puede hablar de leyes y regímenes políticos injustos, cuando atentan contra esos derechos. Es la misma idea contenida en Dworkin, cuando hablan del respeto por la dignidad humana, y en Kaufmann cuando refiere al contenido material del derecho, como elemento fundamental para hablar de la validez de éste. En relación con quienes niegan la ley natural y el derecho natural por considerarlos peyorativamente "metafísicos", quisiera insistir en que la naturaleza humana y sus fines no son conceptos abstractos, ininteligibles e incognoscibles, por el contrario, denotan la misma realidad humana y, por ende, se fundan en hechos de la experiencia, que pueden ser conocidos por todos, como seres racionales que somos (Hervada, 2000, p. 49). Por lo tanto, esa ley y derechos naturales no son un producto de la racionalidad humana, sino que dicha racionalidad los puede conocer. Es por eso que estos preceptos y derechos contenidos en la ley natural y en el derecho natural, al no ser una creación humana y dada la trascendencia de su contenido, no pueden ser excluidos de la reflexión sobre el derecho y la justicia de un plumazo, simplemente tildándolos de "metafísicos".

En consecuencia, el fundamento del Derecho para el realismo -tal como se encuentra en Dworkin y Kaufmann- es la persona humana. Solamente que la concepción de persona desde el realismo no permite reducirlo a uno solo de sus radicales; por eso, comparto con Kaufmann la idea de que el hombre es un ser relacional, porque la sociabilidad humana es uno de los radicales de su ser, pero disiento de él cuando pretende reducir al hombre a su sociabilidad. El hombre lo presenta como un ser que, además de ser social, es un ser capaz de sentido, capaz de hacerse fines -es un ser teleológico-; pero además, lo muestra como un ser de acción libre y, como tal, capaz de dominio sobre sí mismo. Precisamente en el propio dominio, radica el fundamento de la dignidad y el distintivo del ser personal. Cuando eso se logra, producto de la educación que conduce a la madurez humana, el hombre comienza a vivir conforme a su dignidad -que no es algo estático, sino dinámico- y alcanza esa bella virtud éticadianoética de la que habló Aristóteles: la frónesis (prudencia). Esta realidad entitativa de la persona es, para el realismo, el concepto clave de la filosofía y de teoría del Derecho, el cual revela, a la vez, su razón de ser y realidad entitativa.

Estos conceptos resultan fundamentales para afrontar la actual sociedad mundial, a la que se le ha puesto la adjetivación de "pluralista" y de "abierta". Frente a tal pluralismo y apertura, algunos administradores de justicia y algunos teóricos del derecho invitan a ser "tolerantes" con el otro, invocando un respeto casi sagrado por el libre desarrollo de su personalidad. Sin embargo, esa tolerancia no puede significar de ninguna manera actuar sobre la base de la irresponsabilidad, porque ello puede terminar dejando secuelas permanentes y profundamente nocivas para la humanidad.

El comportamiento que exige la "sociedad de riesgo" en la que se vive y en la cual se experimenta sobre el ser humano y se juega con él como si fuera un "ratón de laboratorio", no puede llevar a una tolerancia frente a la irracionalidad, que conduce a realizar atentados contra la persona humana -contra su dignidad-, tal como Dworkin y Kaufmann lo refieren, y como la constitución metafísica del ser humano -que ya se explicitó- lo exige. En esa tarea de preservación y defensa, el derecho positivo, como título de derechos, tiene 
mucho por hacer; tiene que empezar por volver un imperativo el respeto por la condición misma del ser humano, que es origen de derechos naturales. En ese sentido, es urgente que frente a la actual sociedad de riesgo mundial, se establezcan principios que, a su vez, se constituyan en máximas de verdad "no negociables", "no reductibles", "no quebrantables", so pena de poner en riesgo la subsistencia y permanencia del hombre mismo sobre la tierra. Dichos principios no pueden tener como fundamento el mero consenso -en aras de garantizar posiciones "democráticas" - o la voluntad de una persona; esos principios se tienen que asentar sobre la realidad metafísica del ser humano, que muestra su "de suyo", y que se impone como el límite que no puede ser rebasado por la ciencia.

Frente a temas tan delicados, como la clonación humana, la posibilidad, por parte de personas del mismo sexo, de constituir una familia, la manipulación de embriones humanos, las pruebas químicas y nucleares que afectan el ecosistema; así como la posibilidad de irrespetar la vida humana y la integridad personal de manera directa a través de las prácticas eugenésicas, eutanásicas o abortivas, porque "como somos libres", es muy importante para los juristas no olvidar los principios y, sobre todo, las verdades que en dichos principios se contienen, a fin de no ceder y caer en relativismos que son muy peligros $y$ que resultan, a todas luces, incompatibles con la dignidad humana. Una dignidad que no puede ser reducida a una libertad de indiferencia, en la cual cada uno cree que puede hacer lo que le plazca, sin ningún referente a su propia realidad personal-metafísica del hombre, que es realidad "humana", y no simplemente "animal".

Por esta razón, me causan tanta preocupación, frases como las de la Corte Constitucional en la sentencia C-355, en la que se afirma:
En efecto, ha sostenido esta Corporación que en aquellos casos en los cuales se emplea argumentativamente la dignidad humana como un criterio relevante para decidir, se entiende que ésta protege: (i) la autonomía o posibilidad de diseñar un plan vital y de determinarse según sus características (vivir como se quiere).

Digo que me preocupan este tipo aseveraciones del alto tribunal, porque no es cualquiera el que lo dice: es nada más y nada menos que el tribunal constitucional que en Colombia tiene un inmenso poder. El hecho de concebir la libertad como "vivir como se quiera", sin un referente a la realidad misma del ser humano, a su unicidad y sustantividad ${ }^{3}$, a su capacidad de sentido y de fin, a su dimensión social y comunitaria que comienza por la vida de familia, que es una institución natural, constituida sobre la base de la unión de un hombre y una mujer, quienes, orgánicamente, vienen preparados por la misma naturaleza, para continuar la especie humana, es irresponsable históricamente $y$, por ende, muy peligroso para una sociedad.

Los efectos nocivos de este tipo de concepciones ya se están dejando ver en la descomposición social que vive nuestro país y que, como padre de familia y como educador, me preocupa altamente, porque no sé en qué grado estará dicha descomposición, cuando mis hijos crezcan y mis alumnos lleguen a desempeñarse en la vida profesional. En ese sentido, es curioso ver cómo todos reconocemos - de una u otra forma- que en nuestra sociedad hay cosas que no andan bien; se escuchan comentarios en ese sentido en los pasillos, en las reuniones familiares, en eventos académicos, etc.; incluso la

3 El término "sustantividad" es empleado magistralmente por el filósofo español Xavier Zubiri para indicar esa realidad sustancial a la que refería el mundo clásico y escolástico. Con dicha noción, Zubiri quiere indicar que en el hombre hay muchas sustancias de orden físico y espiritual que, unidas, constituyen su "sustantividad" que lo hacen un ser único y de especial dignidad dentro del concierto general de los seres que habitan el universo y que, por ello, merece una protección especial. 
gente menos preparada intelectualmente se percata de ese hecho. Sin embargo, nuestras autoridades que -como bien lo decía el Maestro Tomás de Aquino- tienen el cuidado de la comunidad (curam communitatis habet), parecen no darse cuenta de ello. En estos días, he estado pensando en que esa indiferencia, apatía e irracionalidad, son una forma moderna de desviación de poder, la cual es muy nociva y en la que se mezclan la tiranía y la anarquía. Tiranía, porque prácticamente estamos obligados a hacer lo que ellos dicen y anarquía, porque lo que dicen, nos lleva a pensar que estamos sin quién nos guíe hacia la consecución del bien común que es la razón de ser de cualquier sociedad política. $Y$ esto, ihasta cuándo?

Lo cierto es que la realidad del ser humano tiene que ser el límite a cualquier acuerdo, pacto, contrato o decisión administrativa, legislativa o judicial. De acuerdo con Kaufmann "tolerar no significa soportar ni aceptar a cualquier precio: no se puede tolerar la inhumanidad ni la antijuridicidad, como sucedió en el nacionalsocialismo"; yo agregaría que no se puede tolerar el irrespeto por la vida humana, como tampoco se puede aceptar poner en peligro a la familia, constituida por la unión de un hombre y una mujer, toda vez que con ello se está poniendo en riesgo la permanencia y continuidad de la especie humana.

No quisiera finalizar la exposición de estas ideas, sin enfatizar el hecho de que muchos hombres hoy en día no creen más que en sus propias verdades y en su propia concepción de lo bueno, por lo tanto, creen que haciendo uso de su "libertad", pueden pensar y hacer todo lo que quiera; esas verdades y esas concepciones del bien no tienen un referente con la realidad, pues terminan siendo cualquier cosa que sirve para justificar las propias acciones, así resultan altamente nocivas para su vida y la de la sociedad que integran. Por eso, se asiste a una época en la que hay tantas verdades y concepciones del bien, como personas.
Por otra parte, las voces que podrían tener razón, así como referentes objetivos son opacadas y tildadas de antidemocráticas y "poco respetuosas de la libertad del hombre". Ahora bien, esas voces no se pueden acallar, porque negar la existencia de La Verdad y Del Bien es negar la realidad misma, que muestra que sin bien y sin verdad, la sociedad sería un caos; caos al que la humanidad se está acercando. No se necesita ser un sabio o un gran filósofo para entender que sin orden no hay sociedad, porque el orden es uno de sus radicales.

Los autores analizados plantean la urgencia de volver a fundamentar el derecho en la persona; pero con respecto a lo que es la persona, también hay una verdad que emerge de su propio ser y que si no se respeta y se hace valer se está poniendo en riesgo la propia supervivencia de la especie humana. Cuando la verdad y el bien se relativizan y llega al mundo del Derecho, entonces surgen graves riesgos, frente a los cuales no se puede seguir asumiendo posturas tibias o "democráticas" -como las llaman hoy en día-, en razón de sus consecuencias negativas, que ya se están evidenciando.

En virtud de esto, se hace imperativo tener un soporte para el derecho, que sea de contenido material como lo pide Kaufmann y que lleve a tomarse los derechos en serio de las personas, como lo clama Dworkin. Ese fundamento, como bien lo afirman estos filósofos, no puede ser otro que la persona humana. Pero jamás se podrá fundamentar de manera sólida el derecho, si la noción de persona que se tiene hace abstracción de la propia naturaleza humana.

\section{BIBLIOGRAFÍA}

Aquino, Tomás de. (1996) Suma Teológica (Traducción de los Tratados de la ley y de justicia por Carlos Ignacio González, S.J.). México: Porrúa. 
Aquino, Tomás de. (2001) Comentario a la Ética a Nicómaco de Aristóteles (Ana Mallea, traductora y notas de Celia A. Lértora Mendoza, $2^{\text {a }}$ edición). Pamplona: EUNSA.

Aquino, Tomás de. (Sin fecha) Comentario al libro VI de la Metafísica de Aristóteles. Pamplona: EUNSA.

Beuchot Puente, Mauricio. (1997) Ética y Derecho en Tomás de Aquino. México: UNAM.

Cardona, Carlos. (1996) La metafísica del bien común. Madrid: Rialp.

Cathrein, Victor. (1958) Filosofía del Derecho: natural y positivo. Madrid: REUS.

Dworkin, Ronald. (1997) Los derechos en serio (Marta Guastavino, traductora). Barcelona: Ariel.

Dworkin, Ronald. (1988) El imperio de la justicia. Barcelona: Gedisa.

Gilson, Etienne. (1963) El realismo metódico. Madrid: Rialp.

Graneris, Giuseppe. (1973) Contribución tomista a la filosofía del derecho. Buenos Aires: EUDEBA.
Hervada, Javier. (2000) Introducción crítica al derecho natural. Bogotá: Temis.

Hervada, Javier. (1998) Cuatro lecciones de derecho natural. Pamplona: EUNSA.

Kaufmann, Arthur. (1999) Filosofía del Derecho (Luis Villar Borda, traductor). Bogotá: Editorial Univesidad Externado de Colombia.

Millán-Puelles, Antonio. (1997) El interés por la verdad. Madrid: Rialp.

Pieper, Josef. (1998) Las virtudes fundamentales. Madrid: Rialp.

Radbruch, Gustav. (1992) Relativismo y Derecho. Bogotá: Temis.

Villey, Michel. (1979) Compendio de Filosofía del Derecho (2 Tomos). Navarra: EUNSA.

Zubiri, Xavier. (1986) Sobre el hombre. Madrid: Alianza editorial.

Zubiri, Xavier. (1999) El hombre y la verdad. Madrid: Alianza editorial. 